\title{
Effects of Patient-Centered Medical Home Attributes on Patients' Perceptions of Quality in Federally Supported Health Centers
}

Lydie A. Lebrun-Harris, $\mathrm{PbD}, M P H^{1}$

Leigu Sbi, DrPH, MBA, MPA ${ }^{2}$

Jinsheng Zbu, MEc ${ }^{2}$

Matthew T. Burke, $M D^{3}$

Alek Sripipatana, $\mathrm{PbD}, \mathrm{MPH}$

Quyen Ngo-Metzger, MD, MPH

'Office of Research and Evaluation, Office of Planning, Analysis and Evaluation, Health Resources and Services Administration, US Department of Health and Human Services, Rockville, Maryland

${ }^{2}$ Department of Health Policy and Management and Primary Care Policy Center, Bloomberg School of Public Health, Johns Hopkins University, Baltimore, Maryland

${ }^{3}$ Department of Family Medicine, Franklin Square Hospital, Baltimore, Maryland

${ }^{4}$ Office of Quality and Data, Bureau of Primary Health Care, Health Resources and Services Administration, US Department of Health and Human Services, Rockville, Maryland

${ }^{5}$ US Preventive Services Task Force, Center for Primary Care, Prevention, and Clinical Partnerships, Agency for Healthcare Research and Quality, US Department of Health and Human Services, Rockville, Maryland

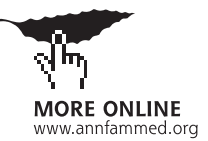

Conflicts of interest: authors report none.

\section{CORRESPONDING AUTHOR}

Lydie A. Lebrun-Harris, PhD, MPH Office of Research and Evaluation Office of Planning, Analysis and Evaluation Health Resources and Services Administration

US Department of Health

and Human Services

5600 Fishers Lane, 10-29

Rockville, MD 20857

llebrun-harris@hrsa.gov

\begin{abstract}
PURPOSE We sought to assess patients' ratings of patient-centered medical home (PCMH) attributes and overall quality of care within federally supported health centers.
\end{abstract}

METHODS Data were collected through the 2009 Health Center Patient Survey $(n=4,562)$, which consisted of in-person interviews and included a nationally representative sample of patients seen in health centers. Quality measures included patients' perceptions of overall quality of services, perceptions of quality of clinician advice/treatment, and likelihood of referring friends and relatives to the health center. PCMH attributes included (1) access to care getting to health center, (2) access to care during visit, (3) patient-centered communication with health care clinicians, (4) patient-centered communication with support staff, (5) self-management support for chronic conditions, (6) self-management support for behavioral risks, and (7) comprehensive preventive care. Bivariate analysis and logistic regressions were used to examine associations between patients' perceptions of PCMH attributes and patient-reported quality of care.

RESULTS Eighty-four percent of patients reported excellent/very good overall quality of services, $81 \%$ reported excellent/very good quality of clinician care, and $84 \%$ were very likely to refer friends and relatives. Higher patient ratings on the access to care and patient-centered communication attributes were associated with higher odds of patient-reported high quality of care on the 3 outcome measures.

CONCLUSIONS More than $80 \%$ of patients perceived high quality of care in health centers. PCMH attributes related to access to care and communication were associated with greater likelihood of patients reporting high-quality care.

Ann Fam Med 2013;508-516. doi:10.1370/afm.1544.

\section{INTRODUCTION}

7 he Health Resources and Services Administration (HRSA) funds health centers through Section 330 of the Public Health Service Act to improve access to primary and preventive care for vulnerable populations. In 2011, 1,128 centers served more than 20 million patients throughout the nation, including $62 \%$ racial and ethnic minorities, $36 \%$ uninsured, $40 \%$ Medicaid-insured, and $93 \%$ below $200 \%$ of the federal poverty level (FPL). ${ }^{1}$ Since the inception of the Health Center Program, HRSA has strived to improve access to high-quality care. As part of its quality initiatives, HRSA began prioritizing the patient-centered medical home (PCMH) model in 2011, and it currently supports health centers in several PCMH transformation initiatives. ${ }^{2-5}$

The medical home is a team-based holistic approach to patient care. It is comprehensive, continuous, coordinated, and accessible, and it promotes quality and safety in an effort to improve health outcomes ${ }^{6-8} \mathrm{~A}$ growing body of literature describes the key features and benefits of the PCMH model..$^{9-12}$ Medical homes may improve health outcomes, reduce disparities in access and quality of care, and ultimately lower costs over time..$^{13-16}$ 
Numerous organizations have developed measures to evaluate key PCMH attributes in health care settings. ${ }^{17}$ Several tools are available, including the National Committee for Quality Assurance's Patient Centered Medical Home tool, currently used by many health centers. ${ }^{17,18}$ This tool was developed for use among primarily privately insured, English-speaking populations, however, and has not been validated with safety-net patients. ${ }^{19}$ The Agency for Healthcare Research and Quality developed a Consumer Assessment of Healthcare Providers and Systems (CAHPS) survey to specifically assess patients' experiences in practices that serve as medical homes (CAHPS $\mathrm{PCMH}){ }^{20,21}$ Safety-net clinicians were included in field testing of the CAHPS $\mathrm{PCMH}_{i}$ however, results from these subpopulations were not analyzed separately from more mainstream practices. In addition, field testing was conducted only in Massachusetts, limiting the findings' generalizability. To address the gap of $\mathrm{PCMH}$ measurement in safety-net clinics, Birnberg and colleagues developed the Safety Net Medical Home Scale (SNMHS). ${ }^{22}$ The SNMHS is administered to administrators and clinicians, rather than patients, so the instrument provides no information about patients' experiences with aspects of the PCMH model.

Additional efforts are needed to reflect health centers' unique social and organizational contexts and to describe patients' experiences with PCMH in safetynet settings. Patient-reported data have increasingly been recognized as valuable sources of information in evaluating health care clinicians and practices. ${ }^{20}$ Although comprehensive data on PCMH in health centers are not yet collected, other data sources are available to provide an indication of how certain attributes of PCMH are experienced by health center patients and whether these attributes are associated with patients' perceptions of quality in this setting. One such data source is the 2009 Health Center Patient Survey, which is based on a random sample of patients seen in health centers across the nation.

The purpose of this study was to assess health center patients' perceptions of key PCMH attributes and quality of care. The specific objectives were to (1) use data from the patient survey to identify patients' perspectives on $\mathrm{PCMH}$ attributes, (2) assess patient perceptions of quality of care in health centers, and (3) examine how PCMH attributes are associated with patient-reported quality of care.

Measuring patients' perspectives of quality is important because these subjective measures of satisfaction relate to objective measures of quality. For instance, patients who view their care positively are more likely to cooperate with their clinicians and follow recommendations, leading to better outcomes. ${ }^{23-25}$
Patient satisfaction is also associated with greater clinician adherence to clinical practice guidelines, better recovery from symptoms, improved emotional health, and fewer diagnostic tests and referrals. ${ }^{26-29}$ Even though patients may not be able to judge the appropriateness of specific services or technical competence of their clinicians, it remains important to measure their subjective experiences. ${ }^{30-32}$

\section{METHODS}

\section{Data Source}

Data for this study were collected through the 2009 Health Center Patient Survey, which included a nationally representative sample of 4,562 patients. Participants were selected through a 3 -stage sampling process. First, health centers were randomly selected, then eligible clinic sites within each health center, then patients with at least 1 visit in the past year. First-stage sampling was stratified by funding stream (ie, Community Health Center, Health Care for the Homeless, Migrant Health Centers, or Public Housing Primary Care funding), patient volume, census region, urban/rural location, and number of sites per grantee. Overall, 188 grantees were sampled with probability proportional to health center patient volume (91\% participation rate). During second-stage sampling, up to 3 clinic sites per grantee were selected. Data were collected from 432 sites (97\% participation rate). During the third-stage sampling, patients were selected as they entered the clinics and consented to be interviewed for the study.

Interview questions were replicated after other national health surveys, including the National Health Interview Survey, National Ambulatory Medical Care Survey, Medical Expenditure Panel Survey, and National Health and Nutrition Examination Survey. Items focused on sociodemographic characteristics, health conditions, health behaviors, access to health care, utilization of services, and satisfaction with care.

Institutional Review Board and local committee approvals were obtained.

\section{Analysis}

\section{Patients' Perspectives on PCMH Attributes}

There were several survey items in the data set that related to specific PCMH attributes (Table 1). We identified 17 potential items related to access to care and patient-centered communication. To avoid mixing response categories, we recoded and dichotomized all variables of interest. We also recoded missing values ("declined" or "don't know") as 0 to minimize dropped observations. We eliminated 3 of these variables because of low correlation. We then conducted factor analysis with the remaining 14 items and identified 4 
Table 1. Survey Items Relating to Patient-Centered Medical Home Attributes

\begin{tabular}{|c|c|}
\hline Attribute & 2009 Health Center Patient Survey Item \\
\hline \multirow[t]{10}{*}{ Access to care } & How well is health center doing regarding ability to get in to be seen? \\
\hline & How well is health center doing regarding hours center is open? \\
\hline & How well is health center doing regarding convenience of center's location? \\
\hline & How well is health center doing regarding prompt return of calls? \\
\hline & How well is health center doing regarding time in waiting room? \\
\hline & How well is health center doing regarding time in examination room? \\
\hline & How well is health center doing regarding waiting time for test results? \\
\hline & Health center ever helped arrange medical appointments? [excluded from factor analysis because of low correlation] \\
\hline & In past 12 months, delayed/unable to get medical care? [excluded from factor analysis because of low correlation] \\
\hline & Usual source of care when sick? [excluded from factor analysis because of low correlation] \\
\hline \multirow{7}{*}{$\begin{array}{l}\text { Patient-centered } \\
\text { communication }\end{array}$} & Clinician staff (eg, physicians, dentists, physician assistants, nurse practitioners) listens to you? \\
\hline & Clinician staff takes enough time with you? \\
\hline & Clinician staff explains what you want to know? \\
\hline & Nurses and medical assistants answer your questions? \\
\hline & Nurses and medical assistants are friendly and helpful to you? \\
\hline & Other staff is friendly and helpful to you? \\
\hline & Other staff answers your questions? \\
\hline \multirow{25}{*}{$\begin{array}{l}\text { Self-management } \\
\text { support (chronic } \\
\text { disease management, } \\
\text { behavioral risks) }\end{array}$} & At least 1 of the following among patients with high cholesterol: \\
\hline & Ever been told by a doctor or other health professional...to eat fewer high-fat or high-cholesterol foods? \\
\hline & Ever been told by a doctor or other health professional...to control your weight or lose weight? \\
\hline & Ever been told by a doctor or other health professional...to increase your physical activity or exercise? \\
\hline & At least 1 of the following among patients with high blood pressure: \\
\hline & $\begin{array}{l}\text { Ever been told by a doctor or other health professional to...go on a diet or change eating habits to help lower } \\
\text { blood pressure? }\end{array}$ \\
\hline & Ever been told by a doctor or other health professional to...cut down on salt or sodium in diet? \\
\hline & Ever been told by a doctor or other health professional to...exercise? \\
\hline & Ever been told by a doctor or other health professional to...cut down on alcohol use? \\
\hline & During last 6 months, received a telephone call to teach how to take care of high blood pressure? \\
\hline & During last 6 months, received an appointment with a nurse call to teach how to take care of high blood pressure? \\
\hline & During last 6 months, received a visit to teach how to take care of high blood pressure? \\
\hline & Any doctor or nurse given a plan to manage own care at home? \\
\hline & At least 1 of the following among patients with diabetes: \\
\hline & During last 6 months, received a telephone call to teach how to take care of diabetes? \\
\hline & During last 6 months, received an appointment with a nurse call to teach how to take care of diabetes? \\
\hline & During last 6 months, received a visit to teach how to take care of diabetes? \\
\hline & Any doctor or nurse given a plan to manage own care at home? \\
\hline & In past 12 months, anyone at health center talk to you about the health risks of smoking and ways to quit? \\
\hline & Either of the following among patients who are current drinkers: \\
\hline & In past 12 months, discussed alcohol use with your doctor? \\
\hline & In past 12 months, doctor asked you about alcohol use? \\
\hline & Either of the following among patients who used drugs in past year: \\
\hline & In past 12 months, discussed drug use with your doctor? \\
\hline & In past 12 months, doctor asked you about drug use? \\
\hline \multirow[t]{3}{*}{ 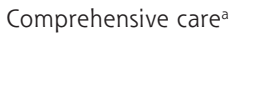 } & Most recent Papanicolaou test? \\
\hline & Most recent mammogram? \\
\hline & Most recent colorectal cancer screening (sigmoidoscopy, colonoscopy, proctoscopy, blood stool test)? \\
\hline
\end{tabular}

attributes, each comprising 3 or 4 items. The score for each attribute was obtained by summing up the scores (0 vs 1 ) of all items within that attribute.

We also separately examined several other variables assessing 3 additional PCMH attributes, namely patient self-management support for chronic conditions (hypercholesterolemia, hypertension, diabetes), patient self-management support for behavioral risks (smoking, alcohol, illicit drugs), and comprehensive care for preventive services (recent screening for cervical, breast, and colorectal cancer) (Table 1). These variables were excluded from factor analysis because the items were 
disease-specific and applied only to smaller subpopulations of interest.

\section{Patients' Perceptions of Quality of Care in Health Centers}

We used the survey data to describe patients' reports of quality in health centers. We compared the distribu tion of PCMH attribute scores across the categories of patient-rated quality of care.

\section{Association Between PCMH Attributes and Patient-} Reported Quality of Care

We conducted logistic regression modeling to explore associations between the various PCMH attributes and patient-reported quality of care while accounting for potential confounding from sociodemographic and health factors. We included a set of covariates in the adjusted models (ie, age, sex, race/ethnicity, insurance, language, poverty, education, health status). These covariates were selected based on literature indicating that patients' perceptions of quality and health care experiences may vary according to these factors.

\section{Outcome Measures}

We examined 3 measures of quality of care, representing global indicators of patients' perceptions of quality: overall quality of services, quality of clinician advice and treatment, and likelihood of referring friends and relatives to the health center. All 3 measures were dichotomously coded in bivariate and multivariate analyses (excellent/very good vs good/fair/poor for the first 2 measures and very likely vs somewhat/not very/ not at all for the third measure). The response "good" was grouped with fair/poor responses because less than $3 \%$ of respondents chose the fair and poor categories. Patient satisfaction and positive perceptions of overall quality have been linked to increased cooperation with clinicians, adherence to recommendations, less medical care, and better outcomes. ${ }^{23-26}$ Information about quality of clinician advice and treatment reflects patients' experiences with actual delivery of care, which they reportedly highly value. ${ }^{33}$ Feedback about referrals is important because patients frequently rely on personal contacts to find primary care services, and these contacts are considered credible sources of information regarding care quality. ${ }^{34,35}$

\section{RESULTS}

Among 8,275 patients initially identified by site receptionists as potential participants, 1,911 declined to participate, and 399 were not screened, leaving 5,965 of selected patients who agreed to participate and were

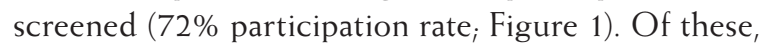

1,323 were excluded, either because they did not have at least 1 previous visit to the health center in the past year, were unaccompanied minors, or the quota for special populations had already been met. Another 80 patients did not complete the interviews.

A total of 4,562 patient interviews were completed between September and December 2009. Computerassisted personal interviews were conducted by trained field interviewers and lasted about 50 minutes. Interviews were conducted in English or Spanish, 95\% of which were on site at the health center and the remainder at another location and time convenient to patients.

\section{PCMH Attributes and Patient-Reported Quality of Care}

A total of $7 \mathrm{PCMH}$ attributes were identified, 4 through factor analysis (Supplemental Table 1, available at www. annfammed.org/content/11/6/508/suppl/DC1) and 3 additional ones. The correlation matrix for the 14 items selected through factor analysis showed that the variables were moderately correlated (Supplemental Table 2, www.annfammed.org/content/11/6/508/suppl/ DC1), and correlations among the 4 selected factors

\section{Figure 1. Patient sample selection process.}

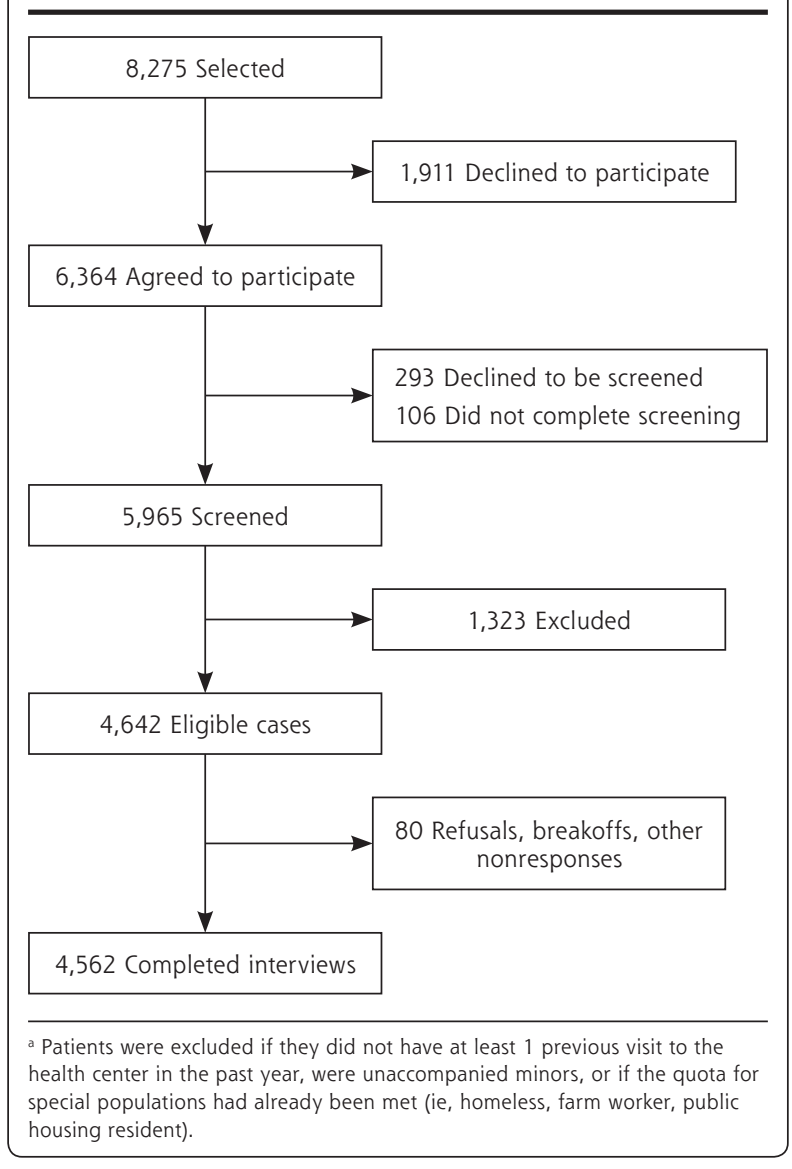


Table 2. Sample Population Distributions $(\mathrm{N}=4,562)$

\begin{tabular}{|c|c|c|c|}
\hline Patient Characteristics and Quality Ratings & Value & Patient Characteristics and Quality Ratings & Value \\
\hline Sociodemographic characteristics & & PCMH attributes, mean score (SE) ${ }^{a}$ & \\
\hline Age, mean (SE), y & $34.2(1.0)$ & Access to care: getting there (range $0-4$ ) & $3.7(0.03)$ \\
\hline Sex, \% (SE) & & Access to care: during the visit (range $0-3$ ) & $2.4(0.04)$ \\
\hline Male & $40.6(2.2)$ & Patient-centered communication: with clinicians & $2.9(0.02)$ \\
\hline Female & $59.4(2.2)$ & & \\
\hline Race/ethnicity, \% (SE) & & $\begin{array}{l}\text { Patient-centered communication: with support staff } \\
\text { (range } 0-4 \text { ) }\end{array}$ & $3.8(0.03)$ \\
\hline African American/Black, non-Hispanic & $21.5(3.9)$ & Self-management support: chronic diseases (range 0-3) & $2.7(0.03)$ \\
\hline Hispanic/Latino & $32.0(4.1)$ & Self-management support: behavioral risks (range $0-3$ ) & $1.5(0.05)$ \\
\hline Other, non-Hispanic & $8.7(1.2)$ & Comprehensive care: preventive services (range 0-3) & $2.2(0.05)$ \\
\hline White, non-Hispanic & $37.8(4.3)$ & Patient ratings of quality of care & \\
\hline Insurance coverage, \% (SE) & & Overall quality of services, \% (SE) & \\
\hline Private & $10.0(1.2)$ & Excellent & $52.9(2.0)$ \\
\hline Medicare & $10.0(0.9)$ & Very good & $30.6(1.9)$ \\
\hline Medicaid & $32.5(3.3)$ & Good & $14.2(2.0)$ \\
\hline Other & $11.0(1.7)$ & Fair & $1.8(0.5)$ \\
\hline Uninsured & $36.5(3.3)$ & Poor & $0.5(0.3)$ \\
\hline Language, \% (SE) & & Quality of physician advice and treatment, \% (SE) & \\
\hline English & $79.0(3.3)$ & Excellent & $52.2(1.8)$ \\
\hline Spanish & $21.0(3.3)$ & Very good & $29.1(1.5)$ \\
\hline Federal poverty level, \% (SE) & & Good & $15.6(1.3)$ \\
\hline$<100 \% \mathrm{FPL}$ & $53.4(2.4)$ & Fair & $2.5(0.5)$ \\
\hline $100-200 \% \mathrm{FPL}$ & $31.6(2.4)$ & Poor & $0.6(0.3)$ \\
\hline$>200 \% \mathrm{FPL}$ & $15.0(2.0)$ & Referrals of friends and relatives to health center, \% (SE) & \\
\hline Education level, \% (SE) & & Very likely & $84.3(1.6)$ \\
\hline High school or higher & $53.0(2.9)$ & Somewhat likely & $11.5(1.1)$ \\
\hline Less than high school & $47.0(2.9)$ & Not very likely & $2.2(0.6)$ \\
\hline General health status, \% (SE) & & Not at all likely & $2.0(0.6)$ \\
\hline Excellent/very good/good & $67.7(2.0)$ & & \\
\hline Fair/poor & $32.3(2.0)$ & & \\
\hline
\end{tabular}

ranged from 0.37 to 0.54 (Supplemental Table 3, www. annfammed.org/content/11/6/508/suppl/DC1).

Table 2 displays patient sociodemographic and health characteristics, mean scores for the 7 final PCMH attributes, and patient-reported quality of care measures. Patients tended to be younger (mean 34 years), female (59.4\%), racially and ethnically mixed (37.8\% non-Hispanic white, 32.0\% Hispanic/Latino, 21.5\% non-Hispanic African American), uninsured (36.5\%) or on Medicaid (33.5\%), English-speaking (79.0\%), and below 200\% FPL (85.0\%). Slightly more than one-half $(53.0 \%)$ of patients had a high school education or higher, and $67.7 \%$ reported excellent, very good, or good health.

Mean scores for the PCMH attributes ranged from 1.5 (of a possible 3.0, with higher scores indicating a better rating) for self-management support (behavioral risks) to 3.8 (of a possible 4.0, with higher scores indicating a better rating) for patient-centered communication (with support staff). Patient ratings of quality of care were high: $52.9 \%$ of patients rated overall quality of services as excellent, and $30.6 \%$ rated it as very $\operatorname{good}_{i} 52.2 \%$ rated the quality of their clinician's advice and treatment as excellent and $29.1 \%$ rated it as very $\operatorname{good}_{i}$ and $84.3 \%$ of patients said they were very likely to refer friends and relatives to the health center.

\section{Associations Between PCMH Attributes and Patients' Perceptions of Quality}

Table 3 provides the distribution of PCMH attribute scores across the 2 levels of quality ratings. Several $\mathrm{PCMH}$ attributes were related to patients' perceptions of quality. In particular, mean scores for 4 of the PCMH attributes ( 2 access to care and 2 patient-centered communication) were consistently higher among patients who reported excellent/very good quality overall care, excellent/very good quality clinician care, and who were very likely to refer friends and relatives to the health center, compared with those who reported lower quality of care and lower likelihood of referrals $(P<.0001$ for all). 
Table 3. Associations Between Patient Ratings of Quality of Care and Perceived Primary Care Medical Home (PCMH) Attributes

\begin{tabular}{|c|c|c|c|c|c|c|c|c|c|}
\hline \multirow[b]{3}{*}{$\begin{array}{l}\text { PCMH } \\
\text { Attributes }^{a}\end{array}$} & \multicolumn{9}{|c|}{ Mean (Standard Error) } \\
\hline & \multicolumn{3}{|c|}{$\begin{array}{l}\text { Perception of Overall } \\
\text { Quality of Services }\end{array}$} & \multicolumn{3}{|c|}{$\begin{array}{l}\text { Perception of Quality of } \\
\text { Clinician Advice and Treatment }\end{array}$} & \multicolumn{3}{|c|}{$\begin{array}{l}\text { Likelihood of Referring Friends } \\
\text { and Relatives to Health Center }\end{array}$} \\
\hline & $\begin{array}{l}\text { Excellentl } \\
\text { Very Good }\end{array}$ & $\begin{array}{l}\text { Goodl } \\
\text { Fair/Poor }\end{array}$ & $P$ Value & $\begin{array}{l}\text { Excellent } / \\
\text { Very Good }\end{array}$ & $\begin{array}{l}\text { Goodl } \\
\text { Fair/Poor }\end{array}$ & $P$ Value & $\begin{array}{l}\text { Very } \\
\text { Likely }\end{array}$ & $\begin{array}{l}\text { Somewhatl } \\
\text { Not Very/Not } \\
\text { at All Likely }\end{array}$ & $P$ Value \\
\hline \multicolumn{10}{|l|}{ Access to care } \\
\hline $\begin{array}{l}\text { Getting there } \\
\text { (0-4 scale) }\end{array}$ & $3.8(0.02)$ & $3.0(0.10)$ & $<.0001$ & $3.8(0.03)$ & $3.2(0.07)$ & $<.0001$ & $3.8(0.03)$ & $3.1(0.12)$ & $<.0001$ \\
\hline $\begin{array}{l}\text { During the visit } \\
\text { (0-3 scale) }\end{array}$ & $2.6(0.04)$ & $1.6(0.07)$ & $<.0001$ & $2.6(0.04)$ & $1.7(0.07)$ & $<.0001$ & $2.6(0.04)$ & $1.7(0.07)$ & $<.0001$ \\
\hline \multicolumn{10}{|c|}{ Patient-centered communication } \\
\hline $\begin{array}{l}\text { With clinicians } \\
\text { (0-3 scale) }\end{array}$ & $3.0(0.01)$ & $2.3(0.09)$ & $<.0001$ & $3.0(0.01)$ & $2.4(0.08)$ & $<.0001$ & $2.9(0.01)$ & $2.4(0.10)$ & $<.0001$ \\
\hline $\begin{array}{l}\text { With support staff } \\
\text { (0-4 scale) }\end{array}$ & $3.9(0.02)$ & $3.2(0.13)$ & $<.0001$ & $3.9(0.02)$ & $3.4(0.11)$ & $<.0001$ & $3.9(0.02)$ & $3.3(0.12)$ & $<.0001$ \\
\hline \multicolumn{10}{|c|}{ Self-management support } \\
\hline $\begin{array}{l}\text { Chronic diseases } \\
\text { (0-3 scale) }\end{array}$ & $2.7(0.03)$ & $2.7(0.10)$ & .6121 & $2.8(0.02)$ & $2.6(0.11)$ & $<.0001$ & $2.7(0.03)$ & $2.7(0.09)$ & .7220 \\
\hline $\begin{array}{l}\text { Behavioral risks } \\
\text { (0-3 scale) }\end{array}$ & $1.5(0.06)$ & $1.4(0.14)$ & .1322 & $1.5(0.06)$ & $1.4(0.15)$ & .0497 & $1.6(0.06)$ & $1.3(0.16)$ & .0001 \\
\hline \multicolumn{10}{|c|}{ Comprehensive care } \\
\hline $\begin{array}{l}\text { Preventive services } \\
\text { (0-3 scale) }\end{array}$ & $2.2(0.06)$ & $2.3(0.10)$ & .1987 & $2.2(0.06)$ & $2.3(0.10)$ & .0053 & $2.2(0.06)$ & $2.3(0.09)$ & .4105 \\
\hline
\end{tabular}

Table 4. Logistic Regression Models: Predictors of Patient-Reported Quality of Care

\begin{tabular}{|c|c|c|c|c|c|c|}
\hline \multirow[b]{2}{*}{$\begin{array}{l}\text { PCMH } \\
\text { Attributes }\end{array}$} & \multicolumn{3}{|c|}{ Unadjusted OR $(95 \% \mathrm{Cl})$} & \multicolumn{3}{|c|}{ Adjusted OR $(95 \% \mathrm{Cl})^{\mathrm{a}}$} \\
\hline & $\begin{array}{l}\text { Perception of } \\
\text { Overall Quality } \\
\text { of Services }^{\mathrm{b}}\end{array}$ & $\begin{array}{c}\text { Perception } \\
\text { of Quality of } \\
\text { Clinician Advice } \\
\text { and Treatment }\end{array}$ & $\begin{array}{l}\text { Likelihood of } \\
\text { Referring Friends } \\
\text { and Relativesc }\end{array}$ & $\begin{array}{l}\text { Perception of } \\
\text { Overall Quality } \\
\text { of Services }^{\mathrm{b}}\end{array}$ & $\begin{array}{c}\text { Perception } \\
\text { of Quality of } \\
\text { Clinician Advice } \\
\text { and Treatment } \\
\text { ab }\end{array}$ & $\begin{array}{l}\text { Likelihood of } \\
\text { Referring Friends } \\
\text { and Relatives }\end{array}$ \\
\hline \multicolumn{7}{|l|}{ Access to care } \\
\hline Getting there & $1.82(1.04-3.21)^{d}$ & $1.33(0.87-2.04)$ & $1.57(0.96-2.57)$ & $1.96(1.18-3.28)^{\mathrm{e}}$ & $1.46(0.88-2.43)$ & $1.72(1.08-2.72)^{\mathrm{d}}$ \\
\hline During the visit & $1.80(1.40-2.31)^{f}$ & $1.70(1.42-2.04)^{f}$ & $1.63(1.26-2.11)^{f}$ & $1.76(1.37-2.26)^{f}$ & $1.83(1.35-2.47)^{f}$ & $1.65(1.38-1.97)^{f}$ \\
\hline \multicolumn{7}{|c|}{ Patient-centered communication } \\
\hline With clinicians & $3.18(1.84-5.50)^{f}$ & $3.54(2.33-5.37)^{f}$ & $2.17(1.44-3.28)^{f}$ & $3.10(2.01-4.79)^{f}$ & $4.16(2.33-7.43)^{f}$ & $2.03(1.30-3.19)^{\mathrm{e}}$ \\
\hline $\begin{array}{l}\text { With support } \\
\text { staff }\end{array}$ & $1.50(1.16-1.94)^{\mathrm{e}}$ & $1.23(0.96-1.58)$ & $1.43(1.20-1.70)^{f}$ & $1.61(1.20-2.18)^{\mathrm{e}}$ & $1.34(0.94-1.90)$ & $1.64(1.29-2.10)^{f}$ \\
\hline \multicolumn{7}{|c|}{ Self-management support } \\
\hline Chronic diseases & $0.76(0.46-1.26)$ & $1.26(0.99-1.60)$ & $0.88(0.61-1.28)$ & $0.67(0.39-1.16)$ & $1.26(0.95-1.68)$ & $0.84(0.53-1.32)$ \\
\hline Behavioral risks & $0.93(0.78-1.12)$ & $0.98(0.79-1.20)$ & $1.08(0.90-1.30)$ & $0.94(0.75-1.18)$ & $0.90(0.77-1.05)$ & $1.06(0.90-1.24)$ \\
\hline \multicolumn{7}{|c|}{ Comprehensive care } \\
\hline $\begin{array}{c}\text { Preventive } \\
\text { services }\end{array}$ & $1.06(0.85-1.32)$ & $0.94(0.78-1.13)$ & $1.06(0.86-1.32)$ & $0.94(0.76-1.16)$ & $0.74(0.58-0.95)^{d}$ & $0.93(0.70-1.24)$ \\
\hline \multicolumn{7}{|c|}{$\mathrm{OR}=$ odds ratio; $\mathrm{PCMH}=$ patient-centered medical home . } \\
\hline \multicolumn{7}{|c|}{$\begin{array}{l}\text { a Adjusted models include covariates for age, sex, race/ethnicity, language, poverty level, education, insurance coverage type, and health status. } \\
\text { b Excellent/very good vs good/fair/poor. }\end{array}$} \\
\hline
\end{tabular}

\section{Logistic Regressions}

Table 4 displays the unadjusted and adjusted models examining associations between the PCMH attributes and patient-rated quality of care. Most of the signifi- cant findings show that higher PCMH scores were associated with better perception of quality by patients (the lone exception being the inverse association between ratings of comprehensive care and quality of 
clinician advice/treatment, which showed borderline significance). After accounting for sociodemographic and health factors, higher scores on the access to care attributes (getting there and during the visit) were associated with higher odds of reporting excellent/ very good overall quality (odds ratio $[\mathrm{OR}]=1.96,95 \%$ CI, $1.18-3.28$ and $\mathrm{OR}=1.76,95 \% \mathrm{CI}, 1.37-2.26$, respectively) and higher odds of being very likely to refer friends and relatives to the health center $(\mathrm{OR}=1.72$, 95\% CI, 1.08-2.72 and $\mathrm{OR}=1.65,95 \% \mathrm{CI}, 1.38-1.97$, respectively). Higher scores on access to care (during the visit) were also associated with higher odds of reporting excellent/very good clinician advice and treatment $(\mathrm{OR}=1.83,95 \% \mathrm{CI}, 1.35-2.47)$.

Higher scores on the patient-centered communication attributes (with clinicians and support staff) were associated with higher odds of excellent/very good overall quality of care rating $(\mathrm{OR}=3.10,95 \% \mathrm{CI}$, 2.01-4.79 and $\mathrm{OR}=1.61,95 \% \mathrm{CI}, 1.20-2.18$, respectively) and higher odds of being very likely to refer friends and relatives to the health center $(\mathrm{OR}=2.03$, $95 \% \mathrm{CI}, 1.30-3.19$ and $\mathrm{OR}=1.64,95 \% \mathrm{CI}, 1.29-2.10$, respectively). Higher scores on communication with clinicians were also associated with higher odds of reporting excellent/very good clinician advice and treatment $(\mathrm{OR}=4.16,95 \% \mathrm{CI}, 2.33-7.43)$.

\section{DISCUSSION}

We sought to examine the relationship between patient perceptions of PCMH attributes and patient-reported quality of care in health centers across the country. Using nationally representative data, we identified 7 PCMH-related attributes from the patients' perspective in the safety-net setting: access to care (getting to the health center, during the visit), patient-centered communication (with clinicians, support staff), selfmanagement support (for chronic conditions, behavioral risks), and comprehensive preventive care.

Health centers scored the highest on $\mathrm{PCMH}$ attributes representing patient communication with clinicians and support staff, followed by access to care in getting to the health center and self-management support for chronic diseases. Overall, $84 \%$ of patients reported excellent or very good overall quality of services, $81 \%$ reported excellent or very good quality of clinician care, and $84 \%$ reported they were very likely to refer friends and relatives to the health center. These high patient ratings among health centers are especially remarkable given that low-income and uninsured patients across the United States generally rate their care much lower. The Commonwealth Fund's 2010 Biennial Health Insurance Survey found that only $35 \%$ of low-income adults and $27 \%$ of unin- sured adults reported excellent or very good quality of care. ${ }^{36}$

After accounting for covariates, the 2 access-to-care attributes and 2 communication attributes remained significantly associated with patients' perceptions of quality of care. These scores indicate that patients' positive ratings of care are heavily influenced by their perceptions of access and communication, which is unsurprising given that these domains are valued by patients and are easily observed and assessed by patients. Clinicians seeking to improve their patients' overall perceptions of health care experiences should focus on improving patients' experiences in getting access to care before and during the visit and on promoting clinician and support staff communication skills.

This study had several limitations. The patient survey was not specifically designed to assess patients' perspectives on $\mathrm{PCMH}$, and we were unable to identify all relevant $\mathrm{PCMH}$ attributes. Specifically, we were not able to examine shared decision making or coordination of care. Although these aspects of patient-centered care are important, patients may be technically limited in their ability to assess them accurately. Our data successfully identified several key functions of medical homes, access and communication, which are particularly salient to patients.

About $95 \%$ of the interviews were conducted at health centers while participants were visiting for medical appointments. High ratings of quality of care may reflect social desirability bias if patients felt pressure to report positively on their health center. In addition, since recruitment took place during patients' appointments at health centers, the sample may have been biased toward patients who visit health centers more often (eg, older, chronically ill patients). Nonresponse bias may have led to more favorable ratings if patients who were sampled were more likely to positively view their experiences than those who were not sampled.

Finally, although previous research has documented associations between positive patient perceptions of care and increased adherence to medical recommendations, higher technical quality of care, and better outcomes, ${ }^{23-29,37}$ other work suggests that patients' ratings may not always be associated with more objective measures of technical quality. ${ }^{38,39}$ Indeed, our study found that patients' reports of certain PCMH attributes (ie, self-management support for chronic diseases and behavioral risks, comprehensive preventive services) were generally not associated with patients' ratings of quality.

Future efforts should expand on the breadth of PCMH attributes currently assessed in health center surveys. Data collection should include additional questions about patients' experiences with all relevant 
PCMH attributes. Efforts are underway to administer the PCMH CAHPS in health centers to determine the applicability of the assessment in safety-net settings. Additional analyses should examine the link between patients' perspectives of PCMH and objective clinical measures. In addition, the data did not allow identification of health centers with PCMH recognition; more studies are needed to examine the independent effect of actual PCMH accreditation on health center patients' reports of health care quality.

This national study is the first to examine patient perspectives on $\mathrm{PCMH}$ attributes in a safety-net setting. There will be mounting interest in patients' experiences with primary care in the coming years, especially in light of growing calls for transparency regarding health care quality and expected increase in demand for services. In our study, a great majority of patients perceived a high quality of care in health centers, and $\mathrm{PCMH}$ attributes pertaining to access to care and communication were associated with greater likelihood of patients reporting high-quality care. The high ratings of $\mathrm{PCMH}$ attributes and quality of care show that health centers are providing services that are well-received by patients. Although health centers have already made strides in important areas of the patient-centered aspects of $\mathrm{PCMH}$, further research is needed to evaluate ongoing efforts to fully transform to more advanced forms of $\mathrm{PCMH}$, complete with proactive, collaborative teams and work flows to support population management. These settings may be well-positioned to adopt the PCMH model in the near future, and HRSA is actively supporting health centers to achieve $\mathrm{PCMH}$ recognition.

To read or post commentaries in response to this article, see it online at www.annfammed.org/content/11/6/508.

Key words: primary care; patient-centered care; health care quality assessment; vulnerable populations

Submitted September 24, 2012; submitted, revised, January 7, 2013; accepted February 1, 2013.

Funding support: The authors acknowledge the financial support for this study by the Health Resources and Services Administration (HRSA) of the US Department of Health and Human Services (HHS) (contract No. HHSH250200646022I).

Disclaimer: The views expressed in this article are those of the authors and do not necessarily reflect the official policies of HHS, HRSA, or the Agency for Healthcare Research and Quality, nor does mention of the department or agencies imply endorsement by the US government.

\section{References}

1. Department of Health and Human Services - Health Resources and Services Administration. Bureau of Primary Health Care. UDS Summary Report 2011.
2. Macrae J. US Department of Health and Human Services. Health Resources and Services Administration. Program Assistance Letter: HRSA Patient-Centered Medical/Health Home Initiative. 2010. http://www.bphc.hrsa.gov/policiesregulations/policies/pdfs/ pal201101.pdf.

3. Health Resources and Services Administration. FY 2012 Supplemental Funding for Quality Improvement in Health Centers. http://www. hrsa.gov/grants/apply/assistance/pcmh. Accessed October 24, 2013.

4. Center for Medicare \& Medicaid Services. Federally Qualified Health Center Advanced Primary Care Practice (FQHC APCP) Demonstration Fact Sheet. http://innovation.cms.gov/initiatives/FQHCs/FQHC-FactSheet.html.

5. Department of Health and Human Services. News Release: Affordable Care Act to support quality improvement and access to primary care for more Americans. 2011. http://www.hhs.gov/news/ press/2011pres/09/20110929b.html.

6. American College of Physicians. What is the Patient-Centered Medical Home? http://www.acponline.org/running_practice/delivery_ and_payment_models/pcmh/understanding/what.htm. Accessed Jun 6, 2012.

7. American Academy of Pediatrics Medical Home Initiatives for Children With Special Needs Project Advisory Committee. Policy statement: organizational principles to guide and define the child health care system and/or improve the health of all children. Pediatrics. 2004;113(5)(Suppl):1545-1547.

8. Dickens M, Green J, Kohrt A, Pearson H. American Academy of Pediatrics Ad Hoc Task Force on Definition of the Medical Home: The medical home. Pediatrics. 1992;90(5):774.

9. Phillips RL Jr, Bronnikov S, Petterson S, et al. Case study of a primary care-based accountable care system approach to medical home transformation. J Ambul Care Manage. 2011;34(1):67-77.

10. Rosenthal TC. The medical home: growing evidence to support a new approach to primary care. J Am Board Fam Med. 2008;21(5): 427-440.

11. Agency for Healthcare Research and Quality. Patient Centered Medical Home Resource Center. http://www.pcmh.ahrq.gov/portal/ server.pt/community/pcmh__home/1483. Accessed May 23, 2012.

12. Patient-Centered Primary Care Collaborative. Joint Principles of the Patient-Centered Medical Home. 2007. http://www.pcpcc.org/ about/medical-home. Accessed May 23, 2012.

13. Peikes D, Zutshi A, Genevro J, Smith K, Parchman M, Meyers D. Early Evidence on the Patient-Centered Medical Home. Prepared by Mathematica Policy Research for the Agency for Healthcare Research and Quality. 2012. http://pcmh.ahrq.gov/portal/server.pt/ gateway/PTARGS_0_12547_957210_0_0_18/Early\%20Evidence\%20 on\%20the\%20PCMH\%202\%2028\%2012.pdf.

14. Starfield B, Shi L. The medical home, access to care, and insurance: a review of evidence. Pediatrics. 2004;113(5)(Suppl):1493-1498.

15. Franks $P$, Fiscella K. Primary care physicians and specialists as personal physicians. Health care expenditures and mortality experience. J Fam Pract. 1998;47(2):105-109.

16. Beal A, Doty M, Hernandez S, Shea K, Davis K. Closing the Divide: How Medical Homes Promote Equity in Health Care-Results from the Commonwealth Fund 2006 Health Care Quality Survey. Washington, DC: The Commonwealth Fund; 2007.

17. Burton R, Devers K, Berenson R. Patient-Centered Medical Home Recognition Tools: A Comparison of Ten Surveys' Content and Operational Details. Washington, DC: The Urban Institute;2012.

18. National Committee for Quality Assurance. Patient-Centered Medical Home. 2011. http://www.ncqa.org/tabid/631/default.aspx. Accessed Jun 6, 2012.

19. Clarke RM, Tseng CH, Brook RH, Brown AF. Tool used to assess how well community health centers function as medical homes may be flawed. Health Aff (Millwood). 2012;31(3):627-635. 
20. Agency for Healthcare Research and Quality. Consumer Assessment of Healthcare Providers and Systems: Developing a CAHPS Clinician \& Group Survey to Measure the Medical Home. September 2010.

21. Scholle SH, Vuong O, Ding $L$, et al. Development of and field test results for the CAHPS PCMH Survey. Med Care. 2012;50(Suppl): S2-S10.

22. Birnberg JM, Drum ML, Huang ES, et al. Development of a safety net medical home scale for clinics. J Gen Intern Med. 2011;26(12): 1418-1425.

23. Vuori H. Patient satisfaction-an attribute or indicator of the quality of care? QRB Qual Rev Bull. 1987;13(3):106-108.

24. Dubina MI, O'Neill JL, Feldman SR. Effect of patient satisfaction on outcomes of care. Expert Rev Pharmacoecon Outcomes Res. 2009;9(5): 393-395.

25. Safran DG, Taira DA, Rogers WH, Kosinski M, Ware JE, Tarlov AR. Linking primary care performance to outcomes of care. J Fam Pract. 1998;47(3):213-220.

26. Stewart M, Brown JB, Donner A, et al. The impact of patientcentered care on outcomes. J Fam Pract. 2000;49(9):796-804.

27. Glickman SW, Boulding W, Manary M, et al. Patient satisfaction and its relationship with clinical quality and inpatient mortality in acute myocardial infarction. Circulation. 2010;3(2):188-195.

28. Jha AK, Orav EJ, Zheng J, Epstein AM. Patients' perception of hospital care in the United States. N Engl J Med. 2008;359(18):1921-1931.

29. Isaac T, Zaslavsky AM, Cleary PD, Landon BE. The relationship between patients' perception of care and measures of hospital quality and safety. Health Serv Res. 2010;45(4):1024-1040.

30. Bowers MR, Kiefe $\mathrm{Cl}$. Measuring health care quality: comparing and contrasting the medical and the marketing approaches. Am J Med Qual. 2002;17(4):136-144.
31. Chin $\mathrm{MH}$, Muramatsu N. What is the quality of quality of medical care measures? Rashomon-like relativism and real-world applications. Perspect Biol Med. 2003;46(1):5-20, discussion 21-23.

32. Prehn RA, Mayo H, Weisman E. Determining the validity of patient perceptions of quality care. QRB Qual Rev Bull. 1989;15(3):74-76.

33. Mayer T, Cates RJ. Service excellence in health care. JAMA. 1999; 282(13):1281-1283.

34. Tu H, Lauer J. Word of Mouth and Physician Referrals Still Drive Health Care Provider Choice. Washington, DC: Center for Studying Health System Change;2008.

35. Kaiser Family Foundation and Agency for Health Care Research and Quality. National Survey on Americans as Health Care Consumers: An Update on the Role of Quality Information. Menlo Park, CA: Kaiser Family Foundation; 2000.

36. Berenson J, Doty M, Abrams M, Shih A. Achieving Better Quality of Care For Low-Income Populations: The Roles of Health Insurance and the Medical Home in Reducing Health Inequities. Washington, DC: The Commonwealth Fund; 2012.

37. Wennberg JE, Bronner K, Skinner JS, Fisher ES, Goodman DC. Inpatient care intensity and patients' ratings of their hospital experiences. Health Aff (Millwood). 2009;28(1):103-112.

38. Bickell NA, Neuman J, Fei K, Franco R, Joseph KA. Quality of breast cancer care: perception versus practice. J Clin Oncol. 2012;30(15): 1791-1795.

39. Chang JT, Hays RD, Shekelle PG, et al. Patients' global ratings of their health care are not associated with the technical quality of their care. Ann Intern Med. 2006;144(9):665-672. 